\title{
ANALISA POLA SPESIMEN PLASTIK UJI PUKUL CHARPY DENGAN MENGGUNAKAN PRINTER 3D
}

\author{
Etik Puspitasari \\ Jurusan Teknik Mesin Politeknik Negeri Malang \\ etikpuspitasari@yahoo.com \\ (Artikel diterima: Februari 2020, direvisi: April 2020, diterima untuk terbit: Juli 2020)
}

\begin{abstract}
Abstrak - Uji pukul diperlukan untuk mengukur ketangguhan suatu benda yang mana membutuhkan spesimen sebagai material yang akan diuji. Dimana spesimen uji pukul yang biasanya dari logam yang dicetak dengan melakukan pengecoran tidak bisa dibuat sempurna karena sudut-sudut takikannya sangat susah dibuat. Untuk itu peneliti mencoba membuat spesimen dari plastik yang dihasilkan dari printer 3D yang mana takikan atau sudut- sudut pada spesimen uji pukul dapat dibuat dengan presisi menggunakan printer 3D. Desain pola spesimen plastik uji pukul dibuat sesuai standart ASTM dan diuji menggunakan uji Charpy mempunyai panjang 73,6 mm, lebar $12,7 \mathrm{~mm}$ dan tebal $10 \mathrm{~mm}$, takikan berbentuk huruf "V" dengan sudut $45^{\circ}$ posisi ditengah dengan kedalaman takikan sebesar 2,54 mm. setelah itu digambar 3D menggunakan software 3D lalu disimpan dengan format file STL lalu dibuka, disimpan dan diprint di software bawaan dari printer 3D.Adapun variabel yang diteliti adalah tebal layer dan suhu. Analisa spesimen plastik uji pukul dengan menggunakan printer 3D adalah Failed pada tes uji pukul terjadi karena peletakan spesimen pada alat uji pukul charpy peletakan takikan tidak lurus dengan bandul. Seharusnya sudut titik takikan harus lurus dengan bandul dengan cara mengecek posisi yang lurus dengan cara difoto dari belakang dan depan terhadap spesimen dan bandul. Yang kedua diperoleh jika semakin renggang irisan dari dalam spesimen plastik uji pukul menurut jenis tebal layer maka energi yang diberikan harus lebih kecil agar energi yang diserap dapat terbaca pada proses uji pukul charpy. Yang ketiga Pada Spesimen plastik Kode A dan kode B diketahui semakin tebal layer maka energi yang diserap semakin besar. Yang keempat menurut perbedaan suhu nozzle untuk spesimen plastik uji pukul yang disetting menggunakan suhu nozzle $200^{\circ} \mathrm{C}$, energi awal yang diberikan lebih besar dan spesimen lebih kuat menerima beban energi daripada spesimen plastik uji pukul yang disetting menggunakan suhu nozzle $180^{\circ} \mathrm{C}$.
\end{abstract}

Kata kunci: Desain 3D, notch, Plastik, Printer 3D, Spesimen uji pukul Charpy.

\section{Pendahuluan}

Membuat cetakan yang mempunyai pola rumit dengan metode injection moulding terkadang masih mengalami kesulitan. Untuk itu dengan munculnya printer 3D membuat pola atau desain produk yang rumit saat ini begitu mudah. Dengan printer 3D desain yang dibutuhkan cukup diinput ke software gambar kemudian di cetak seperti printer-printer ada umumnya. Berbeda dengan printer umumnya, printer 3D ini mampu mencetak produk sesuai desain dengan tumpukan-tumpukan layer sehingga enghasilkan produk 3D langsung jadi tanpa proses yang lama dan panjang seperti membuat mould/cetakan dari baja terlebih dahulu kemudian ke proses injection moulding yang membutuhkan waktu yang sangat panjang serta biaya yang besar.

Kelebihan printer 3D pekerjaan lebih praktis dan kepresisian hasil produk cukup tinggi. Produk 3D hasil printer cocok dikembangkan sebagai rancangan desain awal atau prototype sebelum kita membuat produk masal. Kelemahan printer 3D ini tidak bisa membuat produk secara masal karena lamanya pembuatan untuk satu produk dapat memakan waktu berjam-jam. Untuk itulah produk hasil printer 3D ini cocok diaplikasikan sebagai produk untuk prototype atau produk dengan kebutuhan sedikit.

Pola hasil pada penelitian ini berbentuk pola spesimen uji pukul yang mana hasil dari printer 3D ini dapat digunakan sebagai praktek pengecoran logam atau alumunium untuk kelas praktek di Jurusan Teknik Mesin Politeknik Negeri Malang yang mana untuk membuat cavity/rongga yang akan dimasukkan cor logam atau alumunium didalamnya sehingga hasil produk dari cor berbentuk sesuai dengan pola awal dari yang dihasilkan dari printer 3D yang terbuat dari plastik.

Spesimen uji pukul dari plastik tersebut memiliki dimensi yang dibuat sesuai standart. Dimana spesimen uji pukul yang biasanya dari logam yang dicetak dengan melakukan pengecoran tidak bisa dibuat sempurna karena sudut-sudut takikannya sangat susah dibuat. Untuk itu peneliti mencoba membuat spesimen dari plastik yang dihasilkan dari printer 3D yang mana takikan atau sudutsudut pada spesimen uji pukul dapat dibuat dengan presisi. Spesimen uji pukul dari plastik ini juga nantinya dapat dipakai untuk membuat mold atau cetakan pada proses pengecoran sehingga dengan dibuatnya spesimen uji pukul yang presisi dan sesuai standar maka diharapkan mahasiswa dalam praktek pengecoran logam dapat berjalan dengan lancar. Selain itu ilmu desain 3D dan ilmu pengoperasian printer 3D dapat diajarkan kepada mahasiswa sehingga dapat menambah ilmu pengetahuan yang baru bagi mahasiswa.

Dengan latar belakang diatas maka peneliti akan mendesain dan membuat pola spesimen plastik uji pukul dengan menggunakan printer 3D yang nantinya dipakai untuk membuat mold untuk pengecoran logam. Kelebihan printer 3D pekerjaan lebih praktis dan kepresisian hasil produk cukup tinggi. Produk 3D hasil printer cocok dikembangkan sebagai rancangan desain awal atau prototype sebelum kita membuat produk masal. Kelemahan printer 3D ini tidak bisa membuat produk secara masal karena lamanya pembuatan untuk satu produk dapat memakan waktu berjam-jam. 
Pola hasil pada penelitian ini berbentuk pola spesimen uji pukul yang mana hasil dari printer 3D ini dapat digunakan sebagai praktek pengecoran logam atau alumunium untuk kelas praktek di Jurusan Teknik Mesin Politeknik Negeri Malang yang mana untuk membuat cavity/rongga yang akan dimasukkan cor logam atau alumunium didalamnya sehingga hasil produk dari cor berbentuk sesuai dengan pola awal dari yang dihasilkan dari printer $3 \mathrm{D}$ yang terbuat dari plastik.

Spesimen uji pukul dari plastik tersebut memiliki dimensi yang dibuat sesuai standart. Dimana spesimen uji pukul yang biasanya dari logam yang dicetak dengan melakukan pengecoran tidak bisa dibuat sempurna karena sudut-sudut takikannya sangat susah dibuat. Untuk itu peneliti mencoba membuat spesimen dari plastik yang dihasilkan dari printer 3D yang mana takikan atau sudut-sudut pada spesimen uji pukul dapat dibuat dengan presisi. Spesimen uji pukul dari plastik ini juga nantinya dapat dipakai untuk membuat mold atau cetakan pada proses pengecoran sehingga dengan dibuatnya spesimen uji pukul yang presisi dan sesuai standar maka diharapkan mahasiswa dalam praktek pengecoran logam dapat berjalan dengan lancar. Selain itu ilmu desain 3D dan ilmu pengoperasian printer 3D dapat diajarkan kepada mahasiswa sehingga dapat menambah ilmu pengetahuan yang baru bagi mahasiswa.

Politeknik Negeri Malang sebagai pendidikan tinggi vokasi khususnya jurusan Teknik Mesin mengajarkan tentang desain produk, perancangan dan pengembangan produk serta praktek pengecoran logam yang mana penelitian ini akan berguna bagi mahasiswa Jurusan Teknik Mesin.

Dengan latar belakang diatas maka peneliti akan mendesain dan membuat pola spesimen plastik uji pukul dengan menggunakan printer 3D yang nantinya dipakai untuk membuat mold untuk pengecoran logam.

Uji pukul berfungsi untuk mengukur ketangguhan suatu bahan atas pembebanan pukul atau kejut yang mana uji pukul tersebut telah distandartkan oleh Charpy dan Izod. Contoh pengujian dapat dilihat pada sepotong spesimen yang ditabrak suatu ayunan bandul, dan energi yang dibutuhkan untuk merusaknya adalah yang diukur. (Syamsul,2016)
Ukuran spesimen harus memenuhi standart ukuran dan sesuai material dari spesimen tersebut biasanya yang dipergunakan standart ASTM, terlebih lagi untuk standart dan pengujian material plastik juga menggunakan standart ASTM (peraro,2000). Standart spesimen plastik ukuran persegi empat yaitu $12,7 \mathrm{~mm}$ kali panjangnya 6,4 tergantung daripada tebal bahan. Selain itu Kecepatan ayun bandul untuk spesimen logam antara 3 dan $4 \mathrm{~m} / \mathrm{s}$ dan untuk bahan plastik kecepatannya lebih rendah dengan $2,44 \mathrm{~m} / \mathrm{s}$. (Syamsul,2016)

Persamaan energi potensial untuk menghitung energi yang diserap material sebagai berikut (Syamsul,2016):

dimana :

$$
\mathrm{Ep}=\mathrm{m} \times \mathrm{g} \times \mathrm{h}
$$

$\mathrm{Ep}=$ energi sebelum tumbukan $(\mathrm{J})$

$\mathrm{m}=$ massa pendulum/bandul $(\mathrm{kg})$

$\mathrm{g}=\operatorname{gravitasi}(\mathrm{m} / \mathrm{s} 2)$

$\mathrm{h}=$ tinggi pendulum/bandul sebelum tumbukan terhadap acuan (m)

atau juga bisa dirumuskan dengan :

$$
\begin{aligned}
& E p=\text { Ep' + EI } \\
& \text { m.g.h = m'.g'.h' + EI } \\
& \text { EI = Ep - Ep' }
\end{aligned}
$$

dimana :

$\mathrm{Ep}=$ energi sebelum tumbukan $(\mathrm{J})$

Ep' $=$ energi setelah tumbukan $(\mathrm{J})$

$\mathrm{EI}=$ energi Impact

h' = tinggi pendulum/bandul sesudah tumbukan (m)

a. Mencari nilai $\mathrm{h}$ :

$\mathrm{x}=\cos \alpha$. panjang lengan Uji pukul Charphy

$\mathrm{L}=\mathrm{h}+\mathrm{x}$

$\mathrm{h}=\mathrm{L}-\mathrm{x}$

b. Mencari nilai h' :

$\mathrm{x}=\cos \alpha$. panjang lengan Uji pukul Charphy

$\mathrm{L}=\mathrm{h}^{\prime}+\mathrm{x}$

$h^{\prime}=\mathrm{L}-\mathrm{x}$

c. Mencari nilai EI

$\mathrm{EI}=\mathrm{Ep}-\mathrm{Ep}$ '

$=(\mathrm{m} \cdot \mathrm{g} \cdot \mathrm{h})-\left(\mathrm{m}^{\prime} \cdot \mathrm{g}^{\prime} \cdot \mathrm{h}^{\prime}\right)$

d. Mencari nilai HI

$A=$ (lebar spesimen-panjang kedalaman takikan)

$\mathrm{x}$ tebal

e. $\mathrm{HI}=\frac{E I}{A}$ 
II. METODE

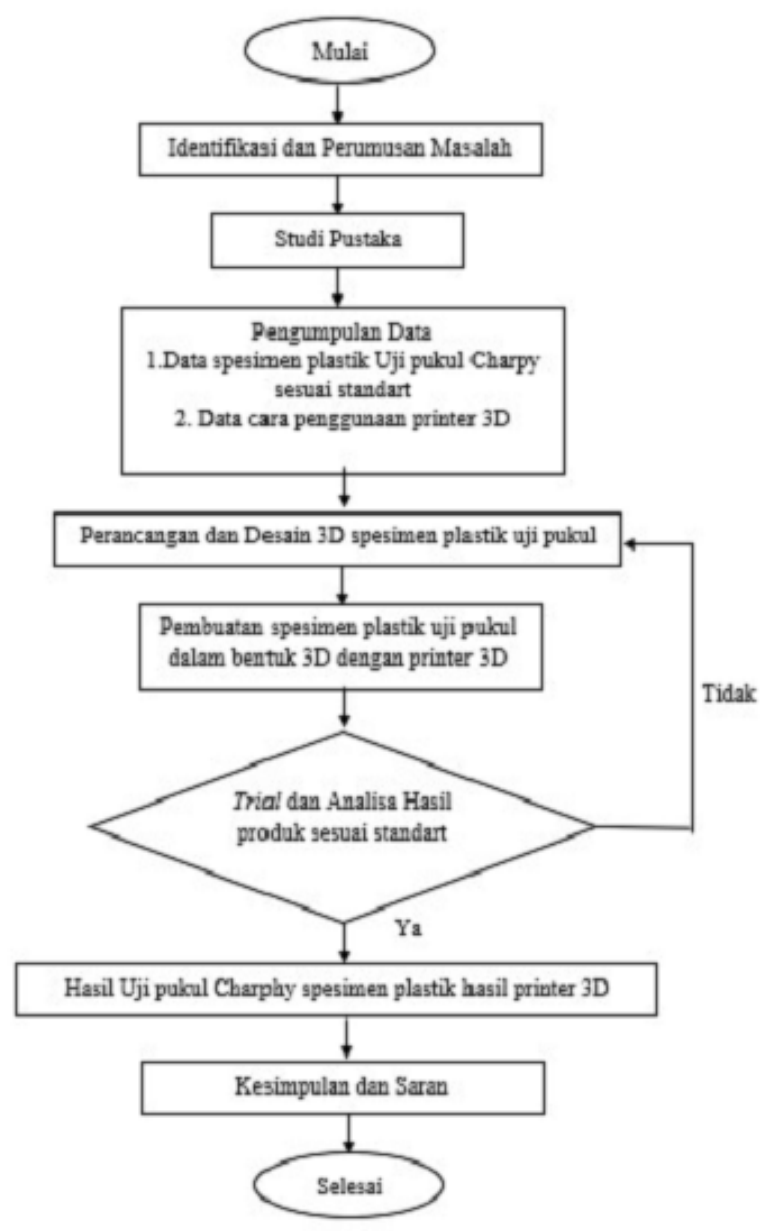

Gambar. 1 Diagram Alir Penelitian

\section{HaSil dan PEMbahasan}

\section{Desain Spesimen Plastik Uji Pukul}

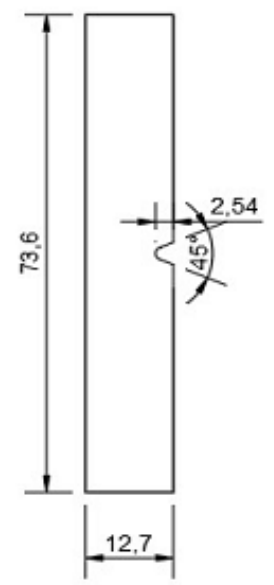

Gambar 2 Gambar 2D Detail spesimen plastik Uji pukul Charpy

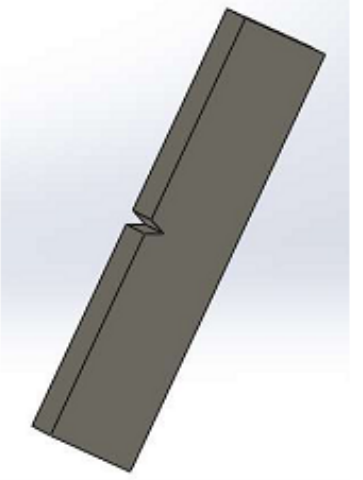

Gambar 3 Gambar 3D Detail spesimen plastik Uji pukul Charpy

\section{Alat Penelitian dan Proses Pembuatannya}

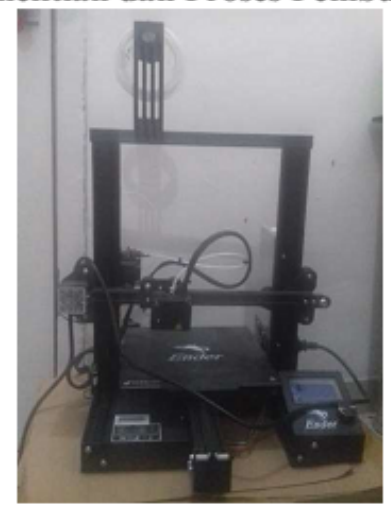

Gambar 4 Printer 3D Tampak Depan

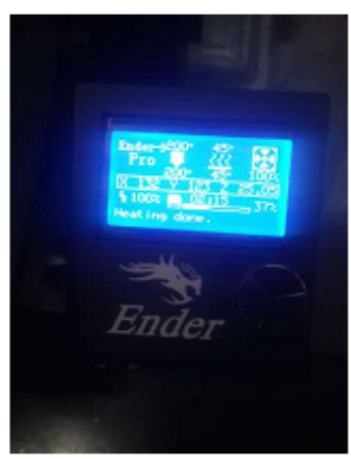

Gambar 5 Program dalam Printer 3D

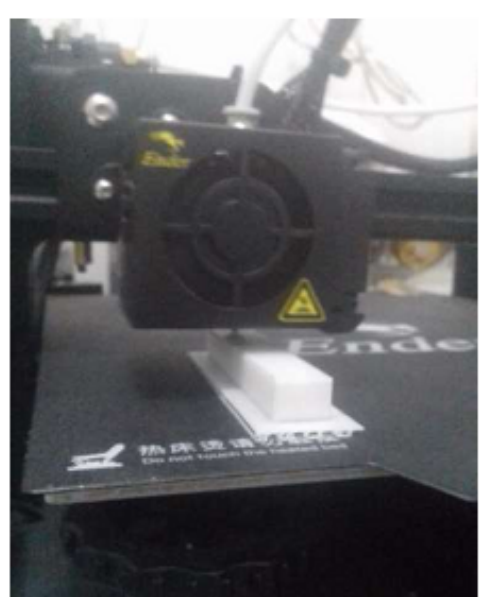

Gambar 6 Proses pembuatan Spesimen A1-1 


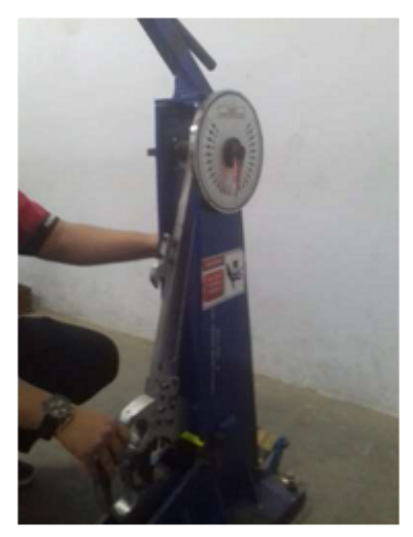

Gambar 7 Alat Uji Pukul Charpy

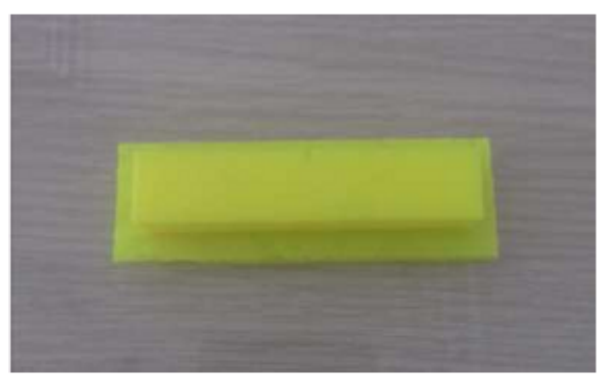

Gambar 8 Contoh Hasil Spesimen Uji Pukul Charpy Dengan Printer 3D Yang Masih dengan Landasan Cetakan

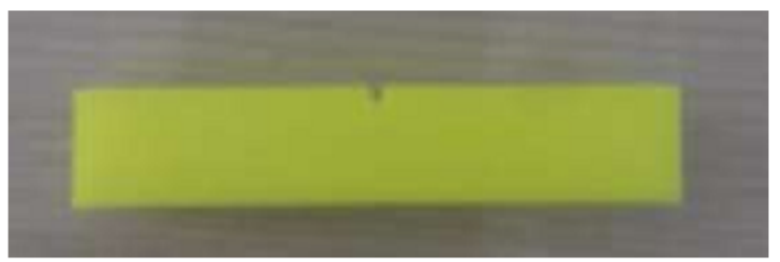

Gambar 9 Contoh Hasil Spesimen Uji Pukul Charpy Dengan Printer 3D

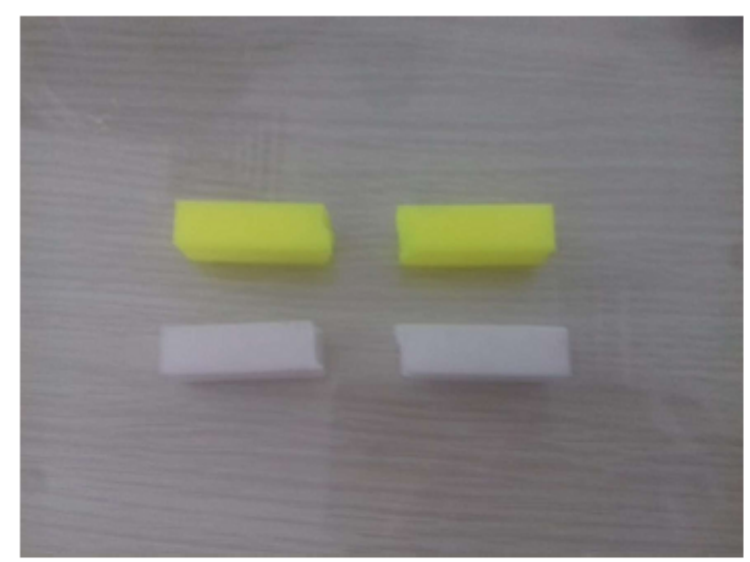

Gambar 10 Contoh Hasil Uji Pukul Charpy Al

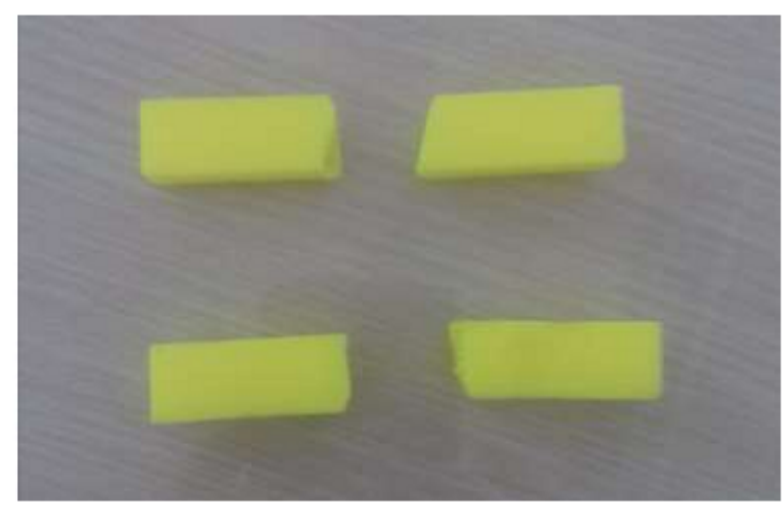

Gambar 11 Contoh Hasil Uji Pukul Charpy B1

\section{Hasil Perhitungan EI dan HI}

\begin{tabular}{|c|c|c|c|c|c|c|c|c|}
\hline $\mathrm{N}_{0}$ & \begin{tabular}{|c|} 
Kode \\
Spesimen \\
Plastik
\end{tabular} & $\begin{array}{c}\text { Suhu } \\
\text { Noztle } \\
\text { (C) }\end{array}$ & $\begin{array}{l}\text { Tebal } \\
\text { Layer } \\
(\mathrm{mm})\end{array}$ & $\begin{array}{c}\text { Tinggi } \\
\text { Awal (h) } \\
\text { (derajat) }\end{array}$ & $\begin{array}{c}\text { Tinggi } \\
\text { Akhir (h') } \\
\text { (derajat) }\end{array}$ & \begin{tabular}{|c} 
EI \\
(Joule)
\end{tabular} & $\begin{array}{c}\text { HI } \\
\text { (Joule/mm2) }\end{array}$ & $\begin{array}{l}\text { Jenis } \\
\text { Patahan }\end{array}$ \\
\hline 1 & $\mathrm{Al}-\mathrm{l}$ & 200 & 0,1 & 20 & 18 & 49,216 & 0,491 & Getas \\
\hline 2 & $\mathrm{Al}-2$ & 200 & 0,1 & 20 & 18 & 49,216 & 0,491 & Getas \\
\hline 3 & $\mathrm{~A} 2-1$ & 200 & 0,15 & 20 & 16 & 98,431 & 0,981 & Getas \\
\hline 4 & A2.2 & 200 & 0,15 & 20 & 16 & 98,431 & 0,981 & Getas \\
\hline 5 & A3-1 & 200 & 0,2 & 20 & 20 & 0,000 & 0,000 & Getas \\
\hline 6 & A3-2 & 200 & 0,2 & 18 & 14 & 98,431 & 0,981 & Getas \\
\hline 7 & BI-1 & 180 & 0,1 & 20 & 18 & 49,216 & 0,491 & Getas \\
\hline 8 & $B 2-2$ & 180 & 0,1 & 20 & Falled & . & . & Getas \\
\hline 9 & B2-1 & 180 & 0,15 & Failed & Failed & . & . & Getas \\
\hline 10 & $B 2-2$ & 180 & 0,15 & 18 & 14 & 98,431 & 0,981 & Getas \\
\hline 11 & B3-1 & 180 & 0,2 & 20 & Falied & . & . & Getas \\
\hline 12 & $B 3-2$ & 180 & 0,2 & 16 & 14 & 49,216 & 0,491 & Getas \\
\hline
\end{tabular}

\section{Kesimpulan}

1. Desain pola spesimen plastik uji pukul dibuat sesuai standart ASTM dan diuji menggunakan uji Charpy. Yang mana mempunyai panjang 73,6 $\mathrm{mm}$, lebar $12,7 \mathrm{~mm}$ dan tebal $10 \mathrm{~mm}$. Selain itu takikan berbentuk huruf "V" dengan sudut $45^{\circ}$ posisi ditengah dengan kedalaman takikan sebesar $2,54 \mathrm{~mm}$. setelah itu digambar 3D menggunakan software 3D lalu disimpan dengan format file STL lalu dibuka, disimpan dan diprint di software bawaan dari printer 3D.

2. Analisa pola spesimen plastik uji pukul dengan menggunakan printer 3D adalah sebagai berikut :

a. Failed pada tes uji pukul terjadi karena peletakan spesimen pada alat uji pukul charphy peletakan takikan tidak lurus dengan bandul. Seharusnya sudut titik takikan harus lurus dengan bandul dengan cara mengecek posisi yang lurus dengan cara difoto dari belakang dan depan terhadap spesimen dan bandul.

b. Sehingga dapat diperoleh hipotesis sementara jika semakin renggang irisan dari dalam spesimen plastik uji pukul menurut jenis tebal layer maka energi yang diberikan harus lebih kecil agar energi yang diserap dapat terbaca pada proses uji pukul charpy 
c. Pada Spesimen plastik Kode A dan kode B diketahui semakin tebal layer maka energi yang diserap semakin besar.

d. menurut perbedaan suhu nozzle untuk spesimen plastik uji pukul yang disetting menggunakan suhu nozzle $200^{\circ} \mathrm{C}$, energi awal yang diberikan lebih besar dan spesimen lebih kuat menerima beban energi daripada spesimen plastik uji pukul yang disetting menggunakan suhu nozzle $180^{\circ} \mathrm{C}$.

\section{Saran}

1. Jika nozzle diawal kotor karena plastik keluar terlebih dahulu dan menggumpal maka segera dibersihkan dengan bantuan gunting agar hasil printer lebih lancar dan baik

2. Jaga roll filament plastik PLA tetap dalam gulungan yang rapi jika tidak maka proses pemakanan roll pada nozzle akan terganggu dan melilit sehingga proses pemakanan berhenti tetapi nozzle tetap berjalan tanpa filament plastik.

3. Levelling printer 3D yang baik agar hasil produk dari printer 3D baik.

4. Jangan menggunakan software bawaan atau builtin software dari printer 3D saja, instal program yang lain untuk hasil variabel yang lebih banyak variasi variabelnya.

\section{DAFTAR PUSTAKa}

[1] Ginting, Rosnani. 2010. Perancangan Produk, Penerbit Graha Ilmu, Yogyakarta.

[2] Hadi Syamsul, 2016. Teknologi Bahan, Penerbit Andi, Yogyakarta.

[3] Hadi Syamsul, 2016. Teknologi Bahan Lanjut, Penerbit Andi, Yogyakarta.

[4] Peraro, James S., and American Society for Testing and Materials. 2000. Limitations of Test Methods for Plastics. ASTM International.

[5] Ulrich, Karl T. and Steven D, Eppinger. 2001.

[6] Perancangan dan Pengembangan Produk. Jakarta: Salemba Teknik 